\title{
1-506-1
}

\section{Trends in and challenges for a bachelor's degree in nursing education: A focus on revisions to the new curriculum}

\section{Yoshiyuki Takahashi}

Ministry of Education, Culture, Sports, Science and Technology in Japan

In 2020, the number of universities teaching nursing in Japan reached 274. In recent years, increasing social demand has been seen for nurses who can cope with Japan's declining population, advances in medical care, and communitybased integrated care systems. Therefore, the expectations of recipients of a bachelor's degree in nursing education have been rising. In 2017, the Ministry of Education, Culture, Sports, Science and Technology of Japan published the "Model Core Curriculum for Nursing Education in Japan" and established learning goals that each university can refer to when organizing the curriculum. In October 2020, the "Regulation for Enforcement of the Act on Public Health Nurses, Midwives, and Nurses" was revised and the total number of credits was increased, and one unit was added to enhance the foundation of clinical judgment when applying pharmacological knowledge. The revision of this regulation provides a good opportunity for universities to revise their own curriculums. It is important both to consider carefully how a curriculum is organized at the basic education stage within a limited period and to create one that attracts students. 